\title{
Findings of Significant Relevance and Improvement Plan in Managing Biomedical Equipment Maintenance at a Complexity III Level Hospital
}

\author{
Nicolas Rocha Hernandez ${ }^{1}$, William Orozco Murillo2*, Jose Alfredo Palacio Fernandez ${ }^{3}$ and \\ Gonzalo Narvaez Benjumea' \\ ${ }^{1}$ Faculty of Exact and Applied Sciences, Instituto Tecnologico Metropolitano, Medellín - Colombia; \\ nicolasrocha204690@correo.itm.edu.co,gonzalonarvaez@itm.edu.co \\ ${ }^{2}$ Department of Electricity and Related Subjects, Pascual Bravo University Institution, \\ Medellin - Colombia. Faculty of Exact and Applied Sciences, Instituto Tecnologico Metropolitano, \\ Medellin - Colombia; william.orozco@pascualbravo.edu.co \\ ${ }^{3}$ Faculty of Engineering, Department of Electronics and Related Subjects, Pascual Bravo University Institution, \\ Medellin -Colombia; josealpa@pascualbravo.edu.co
}

\begin{abstract}
Objectives: To study the hospital maintenance management and metrological characterization of biomedical equipment in the emergency area at a level III hospital, with respect to current legal framework. Methods/Analysis: The emergency area was monitored and information on hospital maintenance management and metrological management was obtained visually; then this information was verified and opportunities for improvement were identified (e.g. in some of the tasks carried out by the maintenance staff) through an instrument designed and provided by the: "Clean Production and Sustainable Consumption" project. It performed quantitative and qualitative assessment of the hospital's management in the emergency service. Findings: This study helped to obtain first-hand information of what actions are being taken (in terms of maintenance management and its articulation with metrological management) at a high medical complexity hospital in Medellin, Colombia contrasted to other 3 hospitals and 2 clinics of the same complexity in which the project had already been implemented. In maintenance management, the institution studied is below the others. This is because it partially meets or does not comply with some evaluation criteria (such as performing predictive maintenance in the emergency service's biomedical equipment or performing maintenance focused on reliability). Concerning metrology and its articulation with maintenance management, the studied institution is below the average. This is because there were items the hospital partially met or did not comply with (such as qualifications or having a prioritizationmaintenance service system in emergency area. Novelty/Improvement: It is recommended that IPS maintain the high scores obtained and re-structure the strategies for the improvement of those sub-items with low performance that reduce the reliability of the work.
\end{abstract}

Keywords: Biomedical Metrology, Hospital Equipment, Maintenance, Medical Emergencies

\section{Introduction}

Instituto Tecnologico Metropolitano, Institucion Universitaria
Pascual Bravo, ACODAL (the Colombian sanitary and environmental engineering association), GSA (Environmental services and management) and other institutions, devel-

${ }^{*}$ Author for correspondence 
oped a research project on cleaner production in Medellin health cluster ${ }^{1}$. One of the objectives of the project is to verify the management of hospital maintenance, since the institutions providing health services are generators of considerable amounts of environmental pollution due to their poor management. According to RESPEL (hazardous waste) classification matrix, that waste materials are type $\mathrm{Y} 1+\mathrm{A} 4020$ (residues from clinics and related) 2 , which contain pathological, sharp and bio sanitary residues, among others. In 2011, this sector produced about 1000 tons in the country ${ }^{\underline{3}}$. In addition to the above pollutants, poor maintenance management would also generate waste of electronic components, spare parts, supplies, oils; these elements are disposed even before their expiration dates. This occurs due to lack of information on the fault history of these elements. Staffs make hasty decisions and the elements are disposed. An adequate maintenance management would allow to have updated fault histories and therefore, disposing these elements would result in reducing the pollutants generated from the maintenance of the biomedical equipment.

In Colombia, IPSs (institutions providing health services) are classified into levels of complexity, according to Article 21, Law 5261 of 19944 . This law establishes the complexity according to the medical procedures performed within the institution.

The emergency service is one of the most important ones managed by a high complexity level IPS. This place receives patients in critical states whose lives are compromised. For this reason, it is important to verify the maintenance of the biomedical equipment in these medical units. Maintenance management is the tool engineering personnel have to carry out pertinent control, planning and management of hospital infrastructure and its staff ${ }^{5}$.

A health service provider institution should comply with the current regulations regarding hospital infrastructure maintenance and its equipment. Electromedical maintenance logs need to be updated, as well as the maintenance protocols and the services provided. Scheduled corrective, preventive and predictive maintenance services, among other aspects, reflect that the maintenance management implemented is adequate and responds effectively according to the level of complexity that the institution is.

Some of the institutions providing health services do comply with the requirements established by a maintenance management system. It is important that all institutions dedicated to provide health services comply with these standards established by national regulations such as Resolution 2003, 2014 (authorization of health services), Resolution 029, 1997 (inspection, surveillance and control) of the resources destined to hospital maintenance), Decree 1595, 2015 (regulations on the national quality subsystem), among others. In this way, trustworthiness to the user over hospital facilities is guaranteed and the quality of health services provided by the institution assured. If these standards are not met, health services could be suspended or disabled; this can increase the crisis suffered by the current health system in Colombia.

The development of this paper characterized hospital and metrological maintenance management including hospital staff of the medical emergency service in a third level clinic. The clinic was assessed and informed about its situation including the current legal framework regarding hospital maintenance and metrological assurance.

\section{Methodology}

The methodology used in this paper consisted of four stages.

\subsection{Stage One}

This stage identified the clinic to be intervened following the guidelines established within the project's framework: "Clean production and sustainable consumption in clinics of Medellin's Health Cluster". This one establishes that the clinic can be private or public and must belong to the health sector in the metropolitan area cluster ${ }^{1}$.

\subsection{Stage Two}

The clinic administration was requested to grant permission to carry out the study. 


\subsection{Stage Three}

The emergency area was visited and inspected in search for the items established in the project.

\subsection{Stage Four}

Regarding the results obtained through the inspection of the items established in the instrument, the calculation of these values is carried out using the following Equation 1:

$$
\mathrm{VP}=(\text { Total Score Obtained }) /(\text { Criteria Evaluated }) \times
$$
100

Being VP the percentage value of the evaluated criteria.

The instrument given by the Clean Production and Sustainable Consumption project "PL + CS" consists of two parts, which are Maintenance and Metrology in biomedical equipment at the emergency area. Both are divided into sections. Maintenance is divided into the following sections: Maintenance planning and maintenance of biomedical equipment. Metrology is divided into the following: Regulations, articulation of maintenance management of biomedical equipment with the metrological assurance plan, Inspection and surveillance ${ }^{1}$.

The instrument is designed with a series of variables in order to facilitate the task of identifying what the clinic does in its daily procedure sat the emergency area.

The instrument, in the first section (Maintenance Planning), contains questions concerning the types of maintenance performed by the clinic, such as predictive maintenance, maintenance focused on reliability, total productive maintenance and questions about the training frequencies for personnel of emergencies when new biomedical technologies are acquired, (Table 1).

The second section (Execution of maintenance) presents questions referring to the protocols to perform

Table 1. Maintenance planning of the biomedical equipment. source: The authors

\begin{tabular}{|c|c|c|c|c|c|c|c|}
\hline & \multirow{3}{*}{$\begin{array}{c}\text { Maintenance of Biomedical } \\
\text { Equipment used at the Emergency } \\
\text { Area }\end{array}$} & \multicolumn{6}{|c|}{ Findings } \\
\hline & & \multirow{2}{*}{$\mathrm{C}$} & \multirow{2}{*}{ N.C } & \multirow{2}{*}{ C.P } & \multicolumn{3}{|c|}{ Observations } \\
\hline & & & & & F & O.M & $\mathbf{R}$ \\
\hline & $\begin{array}{c}\text { Maintenance Planning of Biomedical } \\
\text { Equipment }\end{array}$ & & & & & & \\
\hline 1 & $\begin{array}{c}\text { Is predictive maintenance performed } \\
\text { to the biomedical equipment at the } \\
\text { emergency area? }\end{array}$ & & & & & & \\
\hline 2 & $\begin{array}{l}\text { Is Total Productive Maintenance } \\
\text { (TPM) performed to the biomedical } \\
\text { equipment at the emergency area? }\end{array}$ & & & & & & \\
\hline 3 & $\begin{array}{l}\text { Is Reliability Centred Maintenance } \\
\text { (RCM) performed to the biomedical } \\
\text { equipment at the emergency area? }\end{array}$ & & & & & & \\
\hline 4 & $\begin{array}{l}\text { How often does the medical staff } \\
\text { receive training on new biomedical } \\
\text { technologies used at the emergency } \\
\text { area? }\end{array}$ & & & & & & \\
\hline
\end{tabular}


Table 2. Maintenance execution to biomedical equipment. Source: The authors

\begin{tabular}{|c|c|c|c|c|c|c|c|}
\hline & \multirow{3}{*}{$\begin{array}{c}\text { Maintenance of Biomedical } \\
\text { Equipment used at the Emergency } \\
\text { Area }\end{array}$} & \multicolumn{6}{|c|}{ Findings } \\
\hline & & \multirow{2}{*}{$\mathrm{C}$} & \multirow{2}{*}{ N.C } & \multirow{2}{*}{ C.P } & \multicolumn{3}{|c|}{ Observations } \\
\hline & & & & & F & O.M & $\mathbf{R}$ \\
\hline & $\begin{array}{c}\text { Maintenance Execution of Biomedical } \\
\text { Equipment }\end{array}$ & & & & & & \\
\hline 5 & $\begin{array}{l}\text { Is there a documented and updated } \\
\text { protocol to carry out maintenance on } \\
\text { the biomedical equipment used? }\end{array}$ & & & & & & \\
\hline 6 & $\begin{array}{l}\text { Is corrective maintenance performed on } \\
\text { the biomedical equipment used in the } \\
\text { emergency department? }\end{array}$ & & & & & & \\
\hline 7 & $\begin{array}{c}\text { Is preventive maintenance performed } \\
\text { on biomedical equipment used in the } \\
\text { emergency department? }\end{array}$ & & & & & & \\
\hline 8 & $\begin{array}{l}\text { Is there an up-to-date record and } \\
\text { traceability of the vital signs monitors } \\
\text { available? }\end{array}$ & & & & & & \\
\hline 9 & $\begin{array}{c}\text { Is there an updated record and } \\
\text { traceability of tensiometre maintenance } \\
\text { available? }\end{array}$ & & & & & & \\
\hline 10 & $\begin{array}{c}\text { Is there an updated record and } \\
\text { traceability of defibrillator maintenance } \\
\text { available? }\end{array}$ & & & & & & \\
\hline 11 & $\begin{array}{l}\text { Is documented traceability made to the } \\
\text { antiquity of the biomedical equipment } \\
\text { listed above? }\end{array}$ & & & & & & \\
\hline
\end{tabular}

the corrective and preventive maintenance of some biomedical equipment at the emergency area; some of these variables analysed include: If the equipment have updated records about the activities carried out by the personnel in charge of maintenance. It is also inquired if some equipment such as defibrillators, vital signs monitors and tensiometres have documented traceability according to their seniority; this in order to keep track of the useful life of the equipment, (Table 2).
In Metrology (the second part of the instrument provided), the first section consisted of asking the institution part of the current legal framework. Some questions inquire about whether the equipment in the emergency area such as vital signs monitors, defibrillators and tensiometers are calibrated; if the company that provides this calibration service is certified by the National Organization of Accreditation, (Table 3). 
Table 3. Maintenance execution of biomedical equipment. Source: The authors

\begin{tabular}{|c|c|c|c|c|c|c|c|}
\hline & \multirow{3}{*}{$\begin{array}{c}\text { Metrology and Maintenance } \\
\text { Management of the Biomedical } \\
\text { Equipment at the Emergency Area }\end{array}$} & \multicolumn{6}{|c|}{ Findings } \\
\hline & & \multirow{2}{*}{$\mathrm{C}$} & \multirow{2}{*}{ N.C } & \multirow{2}{*}{ C.P } & \multicolumn{3}{|c|}{ Observations } \\
\hline & & & & & $\mathbf{F}$ & O.M & $\mathbf{R}$ \\
\hline & Regulations & & & & & & \\
\hline 12 & $\begin{array}{l}\text { Does the health unit have permissions, } \\
\text { certifications and accreditations plans to } \\
\text { provide the services? }\end{array}$ & & & & & & \\
\hline 13 & $\begin{array}{l}\text { Are the vital signs monitors calibrated } \\
\text { according to the metrological calibration } \\
\text { parameters? }\end{array}$ & & & & & & \\
\hline 14 & $\begin{array}{c}\text { Are the defibrillators calibrated } \\
\text { according to the metrological calibration } \\
\text { parameters? }\end{array}$ & & & & & & \\
\hline 15 & $\begin{array}{c}\text { Are the tensiometres calibrated } \\
\text { according to the calibration metrological } \\
\text { parameters? }\end{array}$ & & & & & & \\
\hline 16 & $\begin{array}{c}\text { Is the entity in charge of carrying out the } \\
\text { calibration of the biomedical equipment } \\
\text { in the area certified by the competent } \\
\text { authority? }\end{array}$ & & & & & & \\
\hline 17 & $\begin{array}{c}\text { Does the institution have the appropriate } \\
\text { infrastructure in the emergency room for } \\
\text { the adequate care of users? }\end{array}$ & & & & & & \\
\hline 18 & $\begin{array}{l}\text { Are both, electrical and gas networks } \\
\text { in the emergency room serviced and } \\
\text { supervised? }\end{array}$ & & & & & & \\
\hline 19 & $\begin{array}{c}\text { Is there a disposal system for electronic } \\
\text { waste? }\end{array}$ & & & & & & \\
\hline
\end{tabular}

In the second section of the Metrology section (articulation of maintenance management with the metrological assurance plan), the questions or variables consist of determining if they have outsourced equipment at the emergency area. The questions lead to knowing which equipment of this area that are intervened by companies external to the institution. They identify the follow-up that is done to these companies in charge of 
Table 4. Articulation of maintenance management with the metrological assurance plan for biomedical equipment. Source: The authors

\begin{tabular}{|c|c|c|c|c|c|c|c|}
\hline & \multirow{3}{*}{$\begin{array}{l}\text { Metrology and Maintenance } \\
\text { Management of the Biomedical } \\
\text { Equipment at the Emergency Area }\end{array}$} & \multicolumn{6}{|c|}{ Findings } \\
\hline & & & \multirow{2}{*}{ N.C } & \multirow{2}{*}{ C.P } & \multicolumn{3}{|c|}{ Observations } \\
\hline & & & & & $\mathbf{F}$ & O.M & $\mathbf{R}$ \\
\hline & $\begin{array}{c}\text { Maintenance Management of Biomedical } \\
\text { Equipment }\end{array}$ & & & & & & \\
\hline 20 & $\begin{array}{l}\text { Do the personnel responsible for } \\
\text { maintenance management, both technical } \\
\text { and administrative; have the necessary } \\
\text { skills to ensure the achievement of results? }\end{array}$ & & & & & & \\
\hline 21 & $\begin{array}{l}\text { Is there adequate staff (trained, trained } \\
\text { and with the appropriate skills) to } \\
\text { carry out the selected maintenance in } \\
\text { the biomedical equipment used in the } \\
\text { emergency room? }\end{array}$ & & & & & & \\
\hline 22 & $\begin{array}{c}\text { Is there a budget plan to maintain, replace } \\
\text { and update the biomedical equipment at } \\
\text { the emergency room? }\end{array}$ & & & & & & \\
\hline 23 & $\begin{array}{l}\text { Is the calibration of the biomedical } \\
\text { equipment used in the emergency room } \\
\text { articulated with the maintenance of these? }\end{array}$ & & & & & & \\
\hline 24 & $\begin{array}{l}\text { Is there a documented plan for } \\
\text { maintenance management and is it } \\
\text { monitored regularly? }\end{array}$ & & & & & & \\
\hline 25 & $\begin{array}{l}\text { Has the institution contracted the } \\
\text { maintenance of some equipment in the } \\
\text { emergency room? }\end{array}$ & & & & & & \\
\hline 25.1 & $\begin{array}{c}\text { Name of the company that provides the } \\
\text { service: }\end{array}$ & & & & & & \\
\hline 25.2 & $\begin{array}{l}\text { How is the monitoring of these companies } \\
\text { carried out? }\end{array}$ & & & & & & \\
\hline 25.3 & $\begin{array}{l}\text { What is the equipment in the emergency } \\
\text { area that are operated by external } \\
\text { companies? What evidence do you have? }\end{array}$ & & & & & & \\
\hline
\end{tabular}


Table 4 Continued

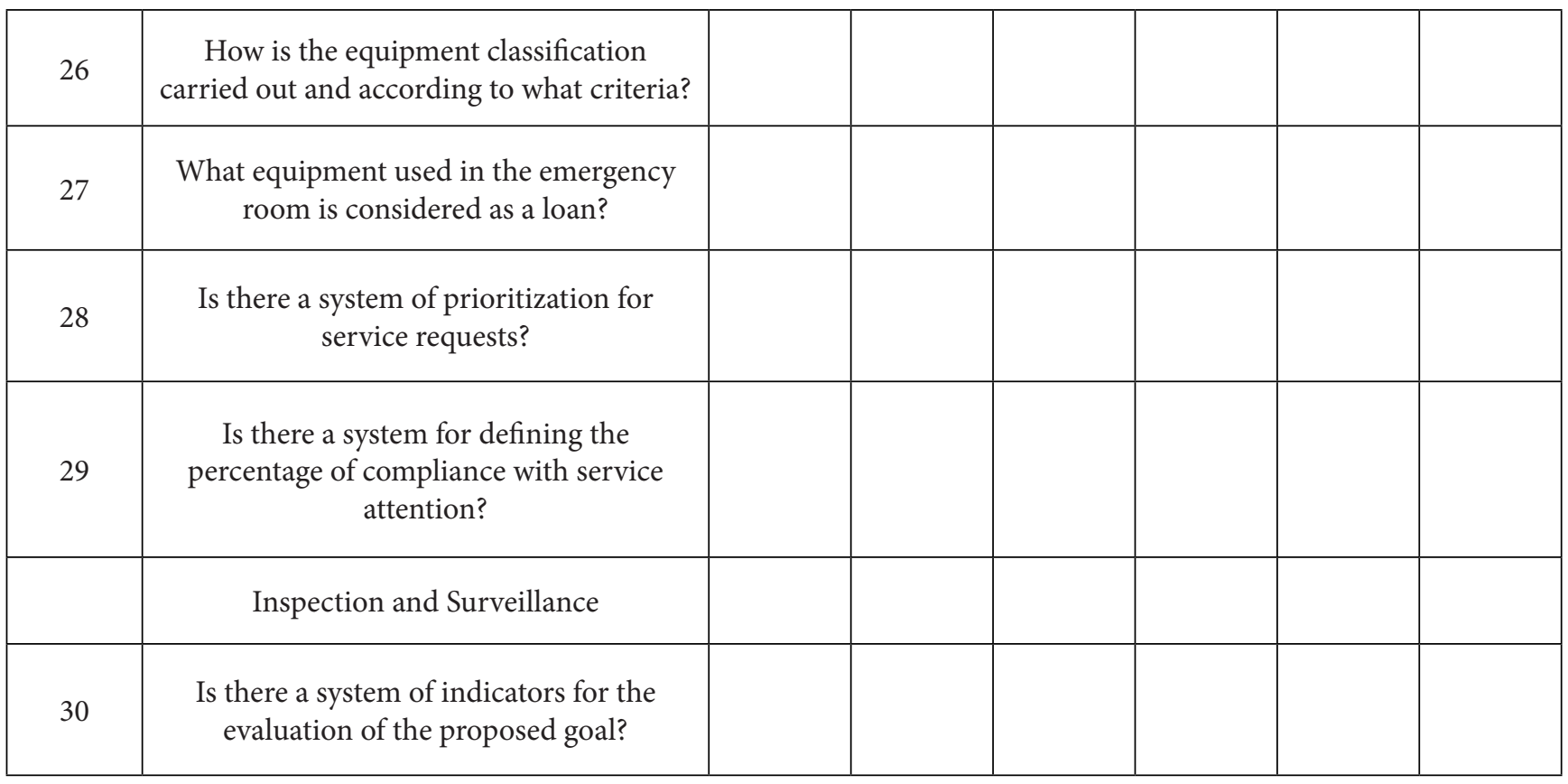

Table 5. Interpretation of the findings. Source: The authors

\begin{tabular}{|l|l|}
\hline \multicolumn{1}{|c|}{ Qualitative Valuation } & \multicolumn{1}{c|}{ Quantitative Valuation } \\
\hline Does not meet & $0 \%$ \\
\hline Insufficient & $1 \%$ to $30 \%$ \\
\hline Acceptable & $31 \%$ to $50 \%$ \\
\hline Good & $51 \%$ to $70 \%$ \\
Very Good & $71 \%$ to $90 \%$ \\
Excellent & $91 \%$ to $100 \%$ \\
\hline
\end{tabular}

providing maintenance services to this equipment. The variables lead to know how the equipment are classified and under what criteria. The last section of Metrology (Inspection and Surveillance) consists of asking the clinic if it has a system of indicators for the evaluation of the proposed goal, such as management, planning, cost, and personnel performance indicators, among others;
(Table 4). The conventions used in the instrument are the following:

C: Fully complies; equals 10 points

C.P: Partially compliant; equals 5 points

N.C: Does not comply; equals 0 points

F: Strength

O.M: Opportunity for improvement 


\section{R: Recommendation}

The corresponding box is marked with an " $\mathrm{X}$ " according to the above conventions, taking into account the maintenance manager's response to each of the aspects established in the application and, once all the fields have been completed, the values are calculated taking into account Equation (1). Once the percentage value is found, we proceed to compare it with the information in Table 5 , to interpret the findings in the health institution.

After comparing the percentage with the qualitative value, the state in which the area evaluated can be identified according to Table 5. This is for establishing improvements if necessary to the work implemented by the IPS in the area evaluated.

\section{Results and Discussion}

The results were obtained through the analysis of the instrument's answers applied at the medical emergency service, which included 5 components: Biomedical equipment maintenance planning, Maintenance execution of medical equipment, Metrology and articulation of the maintenance management of biomedical equipment with the metrological assurance plan in biomedical equipment and Inspection and surveillance.

\subsection{Maintenance Planning Biomedical Equipment}

In the first component, the results are obtained regarding the maintenance planning of biomedical equipment. This item contains a series of variables to identify if the clinic applies predictive maintenance, total productive maintenance, maintenance focused on reliability and training of personnel with the equipment used in the medical emergency service.

Of the 40 possible points, the clinic obtained 25 points; transformed into a percentage value, the clinic obtained $62.5 \%$; comparing this quantitative value to the qualitative one, as indicated in Table 5, it was identified that this result is classified as good. This is because the clinic applies total productive maintenance and personnel training to manipulate the biomedical equipment of the emergency area. The clinic partially fulfills the maintenance focused on the reliability of the biomedical equipment in the emergency area, however, they do not

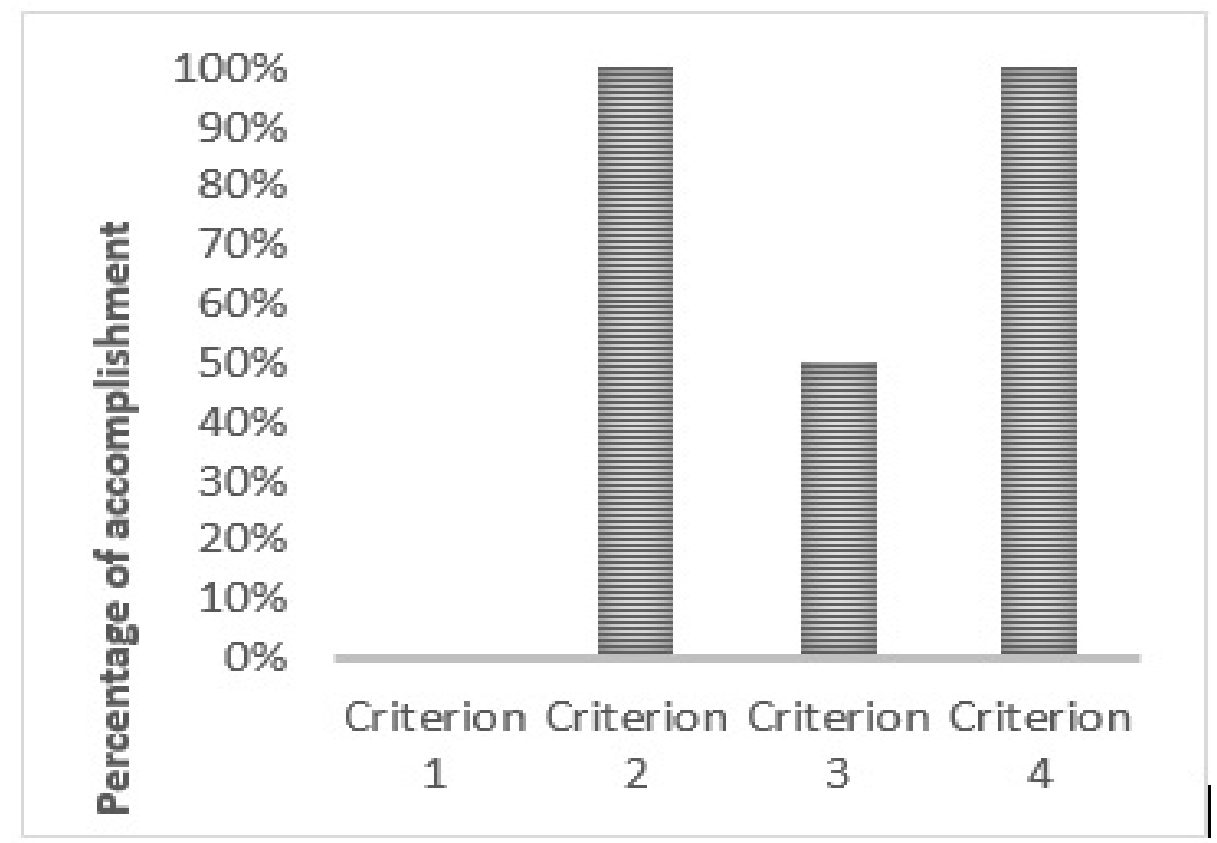

Figure 1. Maintenance planning analysis of biomedical equipment at the emergency area. Source: The authors. 
apply predictive maintenance to emergency department equipments but to those in other areas, such as compressors that distribute the medical air for the entire clinic. Figure 1 shows the results obtained by the clinic when evaluating the first item included in the instructions; it corresponds to the maintenance planning of the biomedical equipment.

In the first evaluation criterion of this first item, the clinic obtained a score of 0 since they stated that they did not perform predictive maintenance to the biomedical equipment used in the emergency area. In the third quarter of this first item, the clinic obtains a half score, this is because it partially complies with the maintenance focused on reliability of the biomedical equipment used in the emergency area.

\subsection{Maintenance Execution of Biomedical Equipment}

In this item, results were obtained on how biomedical management has been carried out by performing maintenance and documenting it. The clinic obtained a percentage value of $100 \%$, catalogued as excellent. The result is because the clinic executes its maintenance plan according to its program.

It is observed in Figure 2 that all the evaluated numerals of this item reach the expected value. It indicates an excellent execution of the maintenance of the biomedical equipment.

\subsection{Metrology and Articulation of the Maintenance Management of Biomedical Equipment with the Metrological Assurance Plan at the Emergency Area}

In this item, the articulation of biomedical metrology with hospital maintenance management was evaluated. The emergency service is one of those that characterizes a clinic of high level of medical complexity; part of the regulations and management of the biomedical equipment was evaluated, taking as reference the section 2.3.2.1 of 2014 Resolution number 2003; the Quick Guide for Measurements in Biomedical Equipment; Decree 4725, 2005; the OIML R-16-1Recommendation; the 17025 ISO's Section 5.10.4, among others. Section 2.3.2.1 indi-

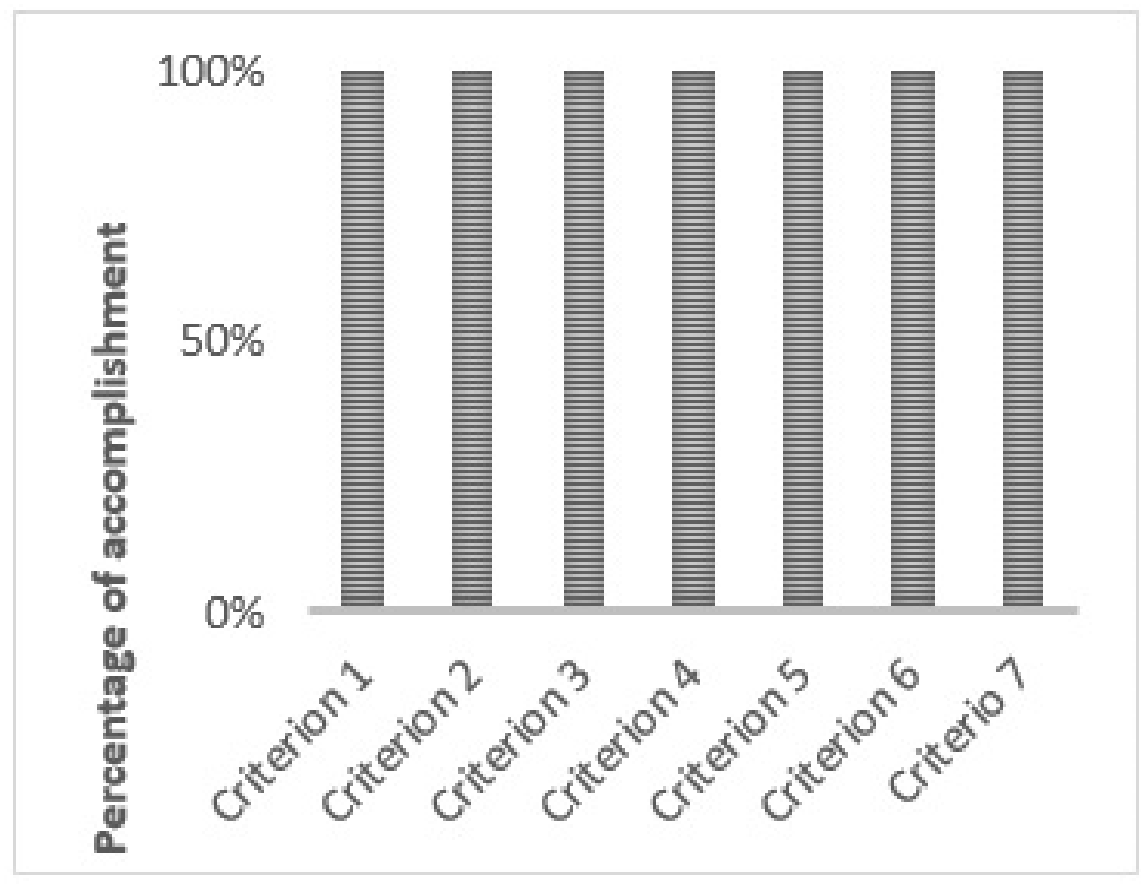

Figure 2. Execution analysis of the maintenance of emergency area equipment. Source: The authors. 
cates that the maintenance of the biomedical, electrical or mechanical equipment must be carried out and must be subjected to a program of periodic preventive checks and calibration of the equipment, all these must be included in the record and must be fulfilled by the service provider ${ }^{6}$.

The Quick Guide for Measurements in Biomedical Equipment is written to clarify which medical equipment is considered a measurement instrument and those that are not considered measurement instruments but have systems or subsystems that are measuring instruments ${ }^{\underline{T}}$. These equipment that are considered or not measurement equipment are being catalogued in the Decree 4725, 2005, which regulates the sanitary registry regime, marketing permit and sanitary surveillance of medical devices for human use ${ }^{8}$.

Biomedical equipment that is considered measuring equipment must be subject to legal metrological controls by the Superintendence of Industry and Commerce (SIC), and the calibration must be performed by a calibration laboratory; which can be accredited by the ONAC; this is indicated by the guide mentioned in the second part.
The biomedical equipment that is not considered measurement instrument but does have systems or subsystems that are measurement instruments indicates that a performance test must be conducted; it contributes to patient safety and is considered a surveillance tool. The performance evaluation is defined as the set of activities that may include measurements which provides the evidence to evaluate in the biomedical equipment: performance, functioning, and technical qualities ${ }^{\underline{7}}$.

An example of biomedical equipment that is not considered a measuring instrument is the vital signs monitor ${ }^{7}$, in which (in the performance tests) medical variables such as blood pressure, temperature, oximetry and heart rate are evaluated. In addition, electrical safety is evaluated following the indications of IEC 60601, which is a series of technical standards in order to protect the patient to avoid an electric shock by the medical Equipment ${ }^{9}$.

Recommendation OIML R-16-1 indicates the procedure to perform the calibration of non-invasive mechanical tensiometrers, using statistical procedures

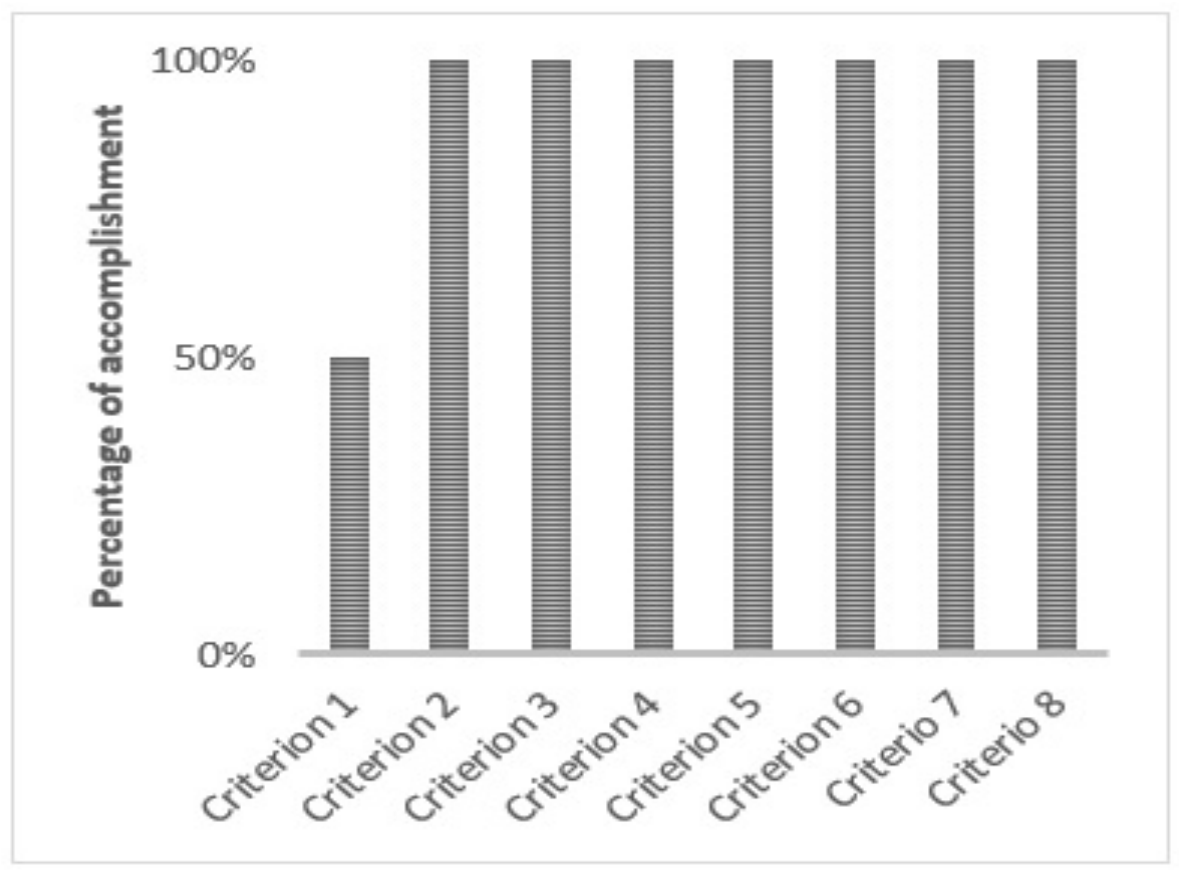

Figure 3. Metrology regulations analysis and maintenance management of the equipment at the emergency area. Source: The authors. 
to establish uncertainty in the measurements $\operatorname{made}^{10}$. The calibration intervals are left to the maintenance manager of the hospital however, the ILAC G-24 offers a guide to keep in mind the guidelines for determining the calibration interval for measurement instruments. Some of them are: The manufacturer's recommendation, influence of the environment and the maximum permissible errors (such as the respective standards) among others ${ }^{11}$.

The ISO/IEC 17025 standard deals with the general requirements for the competence of testing and calibration laboratories; Section 5.10.4 of this standard specifies which information is to be included in the calibration certificate. In our country, the proof that is given to the client of the realization of the calibration is the calibration certificate. When a calibration is made, it is compared to standard equipment and an estimate of the uncertainty is made. The data should be recorded in such a way that trends can be detected ${ }^{12}$. The calibration certificate must have a title, name and address of the laboratory and place where the measurements were taken; the customer's name, identification of the method used the description of the instruments used and other aspects.

By applying the instrument, after evaluating all the items that correspond to this section, it was evident that the clinic has an excellent management of maintenance and metrology for the medical emergency service; it reached 75 points out of the 80 expected. When these scores are taken to the percentage valuation, a value of $93.8 \%$ is obtained.

It can be observed in Figure 3 that in the first criterion of this item, the clinic partially complies with the variable. It corresponds to the enabling, certification and accreditation plans to provide the services. The clinic stated that it is in compliance; but it is not accredited or certified.

\subsection{Articulation of the Maintenance Management of Biomedical Equipment with the Metrological Assurance Plan}

In the evaluation criterion 11 of this fourth item (see Figure 4), it is observed that the clinic does not comply with a system of prioritization for the attention of ser-

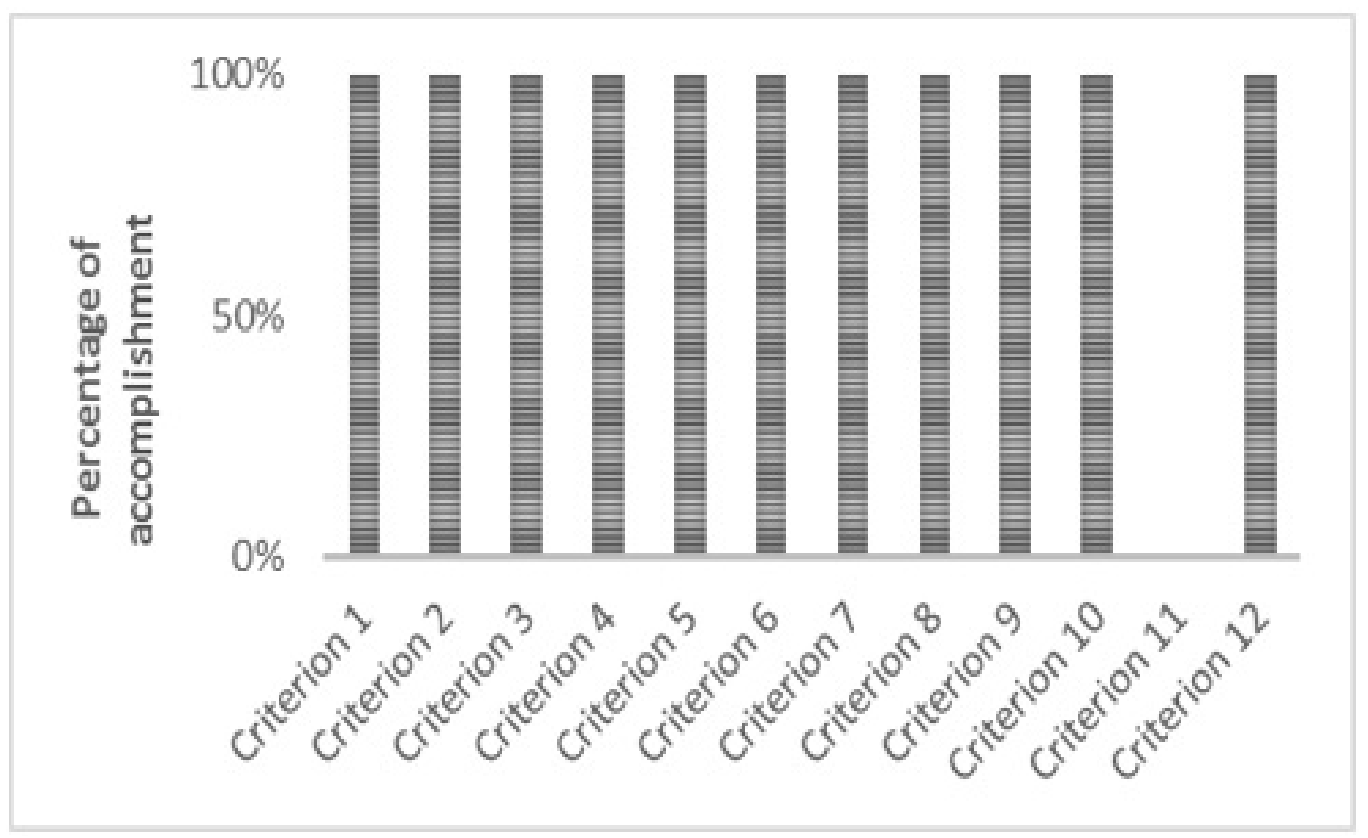

Figure 4. Analysis of the articulation of the maintenance management of biomedical equipment with the metrological assurance plan of the emergency area. Source: The authors. 
vice requests. This becomes important in a clinic with a high level of complexity, such as the clinic evaluated, as this would categorize the maintenance complexity level.

\subsection{Inspection and Surveillance}

Here the implementation of a system of indicators that allow evaluating the proposed goals is inspected. The clinic has this verification system; therefore, it gets a $100 \%$ score. The clinic can access this system through the matrix designed and implemented because they can visualize the maintenance carried out in a month and the difference with what was planned.

In this last item (see Figure 5), it was asked if the clinic has a system of indicators for the evaluation of the proposed goal.

\subsection{Comparison between Hospitals and Clinics}

Since 2014, the project "Clean Production and Sustainable Consumption in Medellin's Health Cluster" has been developing the comparison study and it has conducted it to 3 high levels of medical complexity hospitals and a clinic of high level of complexity. This study was applied to the second clinic which is a high level of medical complexity.

When comparing the results obtained from the second clinic with the results of the other institutions, it can be seen (Figure 6) that, in the maintenance section, this one is below the other institutions. This occurs because they partially or do not comply with some of the evaluation criteria that were established in the instrument, such as performing predictive maintenance in the biomedical equipment of the emergency service or performing maintenance focused on reliability.

Performing predictive maintenance is somewhat costly, however it can be applied to equipment that the institution considers most critical in the emergency service or it can perform these maintenance according to the classification established by Decree 4725, 2005 (which classifies them according to the risk $)^{8,13}$.

It is also observed (in Figure 6) that the results obtained by the clinic for the metrology and maintenance

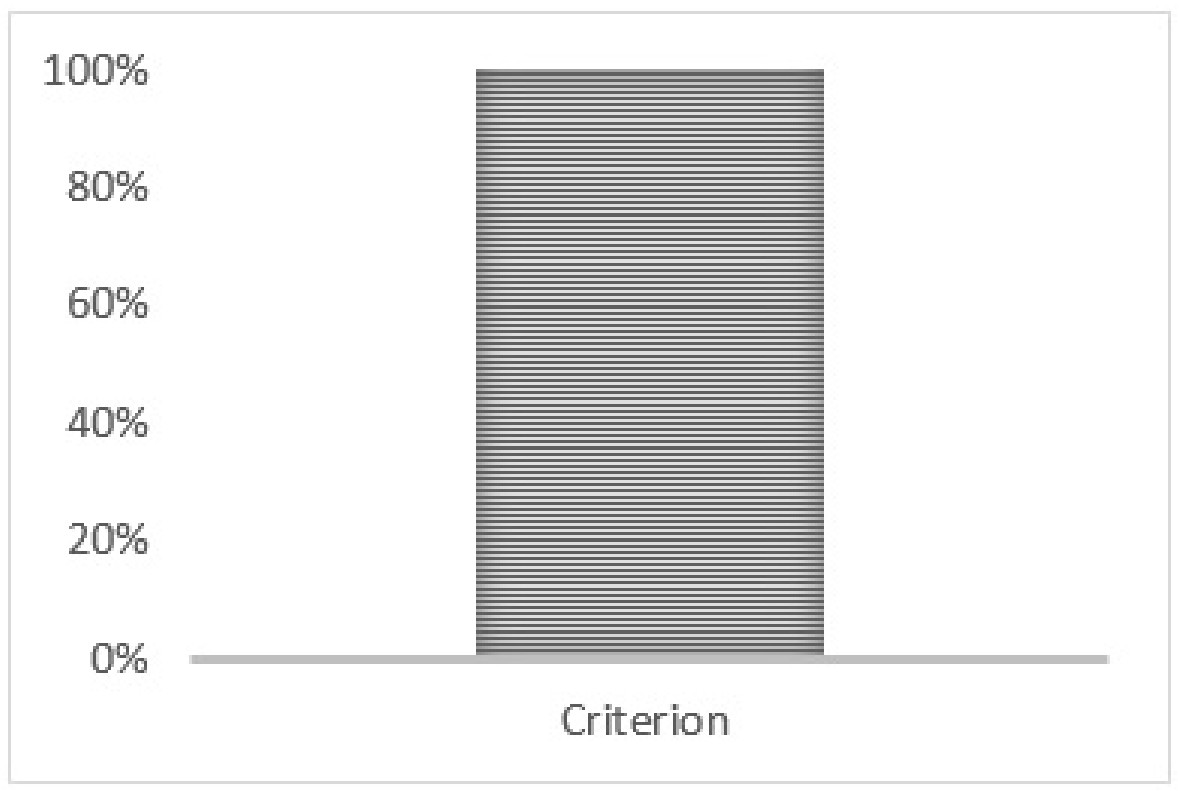

Figure 5. Analysis of the inspection and surveillance of the emergency area equipment. Source: The authors. 


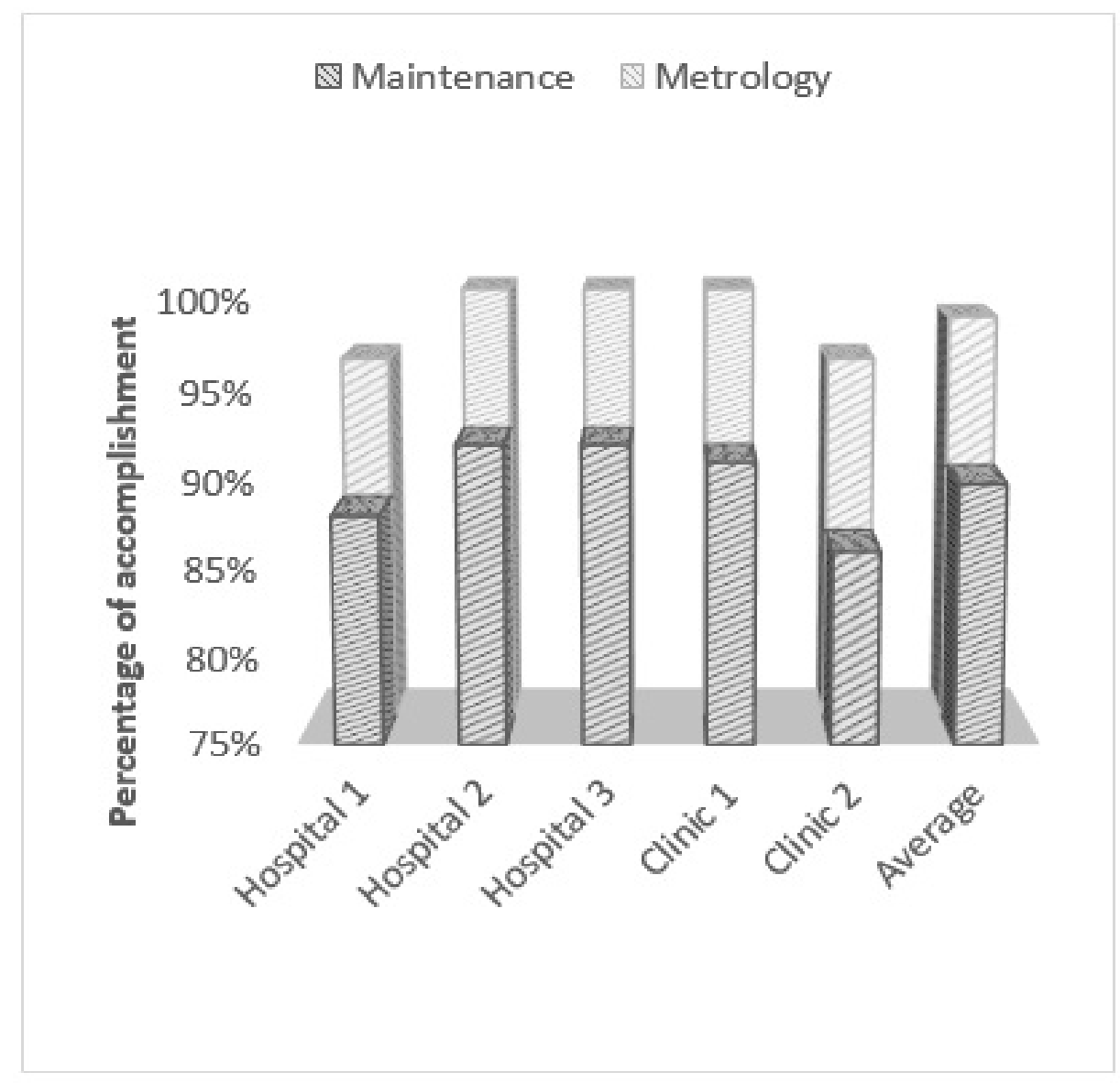

Figure 6. Analysis of the inspection and monitoring of the emergency area equipment. Source: The authors.

management sections are below average. This is because there were items in this section where the clinic partially met or did not comply with, such as being accredited and having a system for the prioritization of maintenance services in the area of medical emergencies.

The average of clinics and hospitals to which the study has been carried out yields interesting results. It is observed that there is a great strength in metrological management and maintenance management in some Medellin IPSs; this shows that they are complying with what is required by the Ministry of Health and the Ministry of Industry and Commerce for assuring the measurement of equipment including equipment that do not measure but have subsystems that do. They compare the average's quanti- tative value for Metrology that is $98.4 \%$. Applying Table 5 to compare values, it is obtained that the Metrological management is excellent in these IPS.

In turn, it is also observed that maintenance has a value close to $90 \%$, if this quantitative value is compared with the qualitative value in Table 5 , it is obtained that the average of the clinics and hospitals is very good. This represents a great contribution for the institutions that participated in this project and for the patients, since they can trust in the maintenance and metrological management that are being carried out in these health entities of the city.

It is recommended that IPS maintain the high scores obtained and re-structure the strategies for the improve- 
ment of those sub-items with low performance that reduce the reliability of the work.

\section{Conclusions}

Considering that all items were evaluated, the overall score of the clinic is calculated by applying Equation (1):

$$
\mathrm{VP}=295 / 31 \times 100=92.2 \%
$$

Then, when comparing the value obtained in, the clinic's qualitative assessment is attained. The clinic does an excellent job; this is due to the excellent management implemented.

During this visit, the aspects that were not known from the academy were identified, such as the categorization of biomedical equipment as established by INVIMA in its Decree 4725, 2005 and also, according to the Emergency Care Research Institute (ECRI). This is a universal system of nomenclature for medical devices, which has been adopted by many nations to name biomedical equipment.

This work served to know firsthand, what is being applied in a clinic of high medical complexity in the metropolitan area of Medellin. The clinic does an excellent job and this is largely due to the actions taken by the new maintenance manager, who designed and began to implement this type of maintenance management matrix in order to obtain more quickly the information of the equipment in the area evaluated and thus expedite the delivery of documents when they perform an audit.

The clinic has great strength in the area of biomedical metrology and it is observed that, this is being articulated with maintenance management within the clinic's maintenance plan. It is observed that from the matrix, you can know the respective documents of the metrological control that is done to biomedical equipment, such as calibration certificates, maintenance protocols, what entity is responsible for carrying out that calibration, if the associated regulations are met, when a calibration is made to an equipment among other; these actions allow greater agility to access information.
Although it is expensive to perform predictive maintenance on all equipment in the emergency area, it is advisable to start by applying it to the equipment that is considered relevant (maintenance such as thermography or vibration analysis that can be applied to the vast majority of equipment found in this area) since this would give support to the task performed by those responsible for carrying out preventive and corrective maintenance.

It is recommended that the clinic implement the prioritization system for maintenance tasks, as this would better allocate the complexity of the work of those responsible for carrying out maintenance. The suggestions for implementing this prioritization system are to categorize by type of maintenance, for example, to perform the corrective first and then perform the preventive ones or prioritize by equipment; this is to prioritize the most used equipment during the day in the emergency area.

\section{References}

1. Narvaez G, Escobar A, Orozco W, Jaramillo C, Ramirez A, Agudelo D. Produccion Mas Limpia, Consumo Sostenible y Gestion de Mantenimiento en el area de Urgencias del cluster de la salud de la ciudad de Medellin. Memorias del XXXIX Congreso Nacional de Ingenieria Biomedica, Mexico. 2016; 3(1):257-8.

2. Area Metropolitana del Valle de Aburra AMVA, Resolucion Metropolitana 0879 de. Por medio de la cual se adopta el Manual Integral de Residuos en el Valle de Aburra como instrumento de autogestion y autorregulacion; 2007.

3. Ministerio de Ambiente y Desarrollo Sostenible.Diagnostico Nacional de Salud Ambiental; Bogota. 2012.

4. Ministerio de Salud.Resolucion Numero 5261 de 5 de agosto, por la cual se establece el Manual de actividades; Bogota.1994.

5. Orozco W, Cortes F. Characterization of the maintenance management of biomedical equipment in emergency services in clinics and hospitals in Medellin period 2008-2009. Revista Ciencias de la Salud. 2013; 11(1):35-44.

6. Ministerio de Salud y Proteccion Social.Resolucion Numero 00002003 de; 2014. p. 228-34.

7. Superintendencia de Industria y Comercio. Guia para las Mediciones en Equipos Biomedicos.Direccion de 
Medicamentos y Tecnologías en Salud Superintendencia de Industria y Comercio; 2015. p. 6-25.

8. Perez Martinez C. Relacion del grado de Compromiso Organizacional y el Desempe-o Laboral en Profesionales de la Salud de un Hospital Publico. Journal of Chemical Information and Modeling. 2013; 53(9):1689-99.

9. IEC 60601-1. Medical design standards for power supplies. International Electrotechnical Commission; 2014. p. 1-14.

10. OIML R 49-1. Water meters for cold potable water and hot water. Part 1: Metrological and technical require- ments. Organisation Internationale De Metrologie Legale. International Recommendation; 2006. p. 1-45.

11. ILAC-G24. Lineamientos para la determinacion de intervalos de calibracion de los instrumentos de medicion. International Laboratory Accerditation Cooperation; Australia. 2007. p. 1-13.

12. ISO/IEC-17025. Requistos generales para la competencia de los laboratorios de ensayo y de calibracion. Norma Internacional. Documento de Trabajo; 2005. p. 1-37.

13. Emergency Care Research Institute (ECRI). 2018. https:// www.ecri.org/about/Pages/History.aspx 